\title{
POLÍTICOS PROFISSIONAIS OU NOBRES POLÍTICOS? VARIÁVEIS DA CARREIRA POLÍTICA DOS SENADORES NO BRASIL IMPÉRIO ${ }^{1}$
}

\section{Ulisses Venâncio ${ }^{2}$}

\begin{abstract}
Resumo: Neste artigo analisamos padrões de carreira política dos senadores no Brasil Império. O tipo de carreira é um importante critério do recrutamento político, e uma proxy da profissionalização política. Uma análise prosopográfica operada com estatística descritiva revelou um padrão de carreiras longas, com muitos cargos, heterogêneas em termos de níveis de poder, e que se intensifica ao longo do período. Isso denota experiência política. O que interpretamos como indício de profissionalização política, tanto dos indivíduos, quanto do Senado. O tema remete ao quanto a política no Império era autônoma frente a outros âmbitos sociais. Os resultados nos obrigam a relativizar a hipótese que levantamos nas teses da historiografia hegemônica: de que o critério decisivo para o recrutamento para o Senado era pertencer ao séquito do Imperador. O estudo reafirma a importância de retomar os principais debates sobre elite e natureza do regime no Brasil imperial.
\end{abstract}

Palavras-Chave: Brasil Império; Senadores brasileiros; Profissionalização Política; Recrutamento.

\begin{abstract}
In this article we analyze political career patterns of senators in Brazil Empire. The type of career is an important criterion of political recruitment, and a proxy of political professionalization. A prosopographic analysis operated with descriptive statistics revealed a pattern of long careers with many positions, heterogeneous in terms of power levels and intensifies over time. This denotes political experience. What we interpret as political professionalization of evidence, both of individuals and the Senate. The theme refers to how much politics in the Empire was autonomous front of other social spheres. The results force us to relativize the hypothesis raised in the theses of the hegemonic historiography: that the decisive criterion for recruitment to the Senate was to belong to the entourage of the Emperor. The study reaffirms the importance of resuming the main debates and elite nature of the regime in Imperial Brazil.
\end{abstract}

Keywords: Brazil Empire; Brazilian senators; Professionalization Policy; Recruitment.

Resumen: En este artículo se analizan los patrones de carrera política de los senadores en el Brasil Imperio. El tipo de carrera es un críterio importante de reclutamiento político, y un proxy de la profesionalización política. Un análisis prosopográfico operado con estadística descriptiva reveló un patrón de largas carreras con muchos puestos, heterogéneas en términos de niveles de poder que se intensifíca con el tiempo. Esto denota experiencia política. Lo que interpretamos como profesionalización política, tanto de los individuos como del Senado. El tema se refiere a saber cuanto la política en el Imperio fue autónoma frente a otras esferas sociales. Los resultados nos obligan a relativizar la hipótesis planteada a partir de las tesis de la historiografía hegemónica: que el criterio decisivo para el reclutamiento al Senado era pertenecer a la comitiva del emperador. El estudio reafirma la importancia de retomar las discusiones principales sobre la élite y la naturaleza del régimen en Brasil Imperial.

Palabras- claves: Brasil Imperio; Senadores brasileños;Profesionalización; Reclutamiento.

\section{INTRODUÇÃO}

A difusão de condutas sociais pautadas na razão é característica essencial da modernização. Uma importante consequência deste processo foi uma maior complexidade na divisão do trabalho social como um todo, com isso, ocorreu o aprofundamento dos conhecimentos e técnicas necessárias para o exercício de cada atividade; incluindo a política. A especialização gerada fez necessários uma burocracia e "modos de fazer" que passou a exigir pessoal com aptidão e valores específicos, logo, com tendência a se dedicar de modo integral e continuado. Neste marco geral se inscreve o tema da profissionalização política.

Como nos aponta Perissinotto e Veiga (2012), há duas vertentes básicas sobre o tema. A primeira é normativa, parte de diferentes pontos do espectro ideológico, e toma o fenômeno como a causa da existência de políticos auto-interessados. Este seria o principal fator da degeneração da "boa política". Mas o problema deontológico não interessa neste estudo. A segunda, a qual os autores acima citados se filiam, e aqui, busca-

${ }^{1}$ Este artigo é parte de uma dissertação de mestrado que será apresentada ao PPGCP (Programa de Pós-graduação em Ciência Política) da UFPR (Universidade Federal do Paraná), que será defendida em fevereiro de 2017.

2 Mestrando em Ciência Política pelo PPGCP da UFPR, bolsista CAPES. 
remos nos filiar, procura analisar o processo de produção dos políticos profissionais entendidos como fruto da autonomia do campo político frente a outros âmbitos sociais.

O mais comum são estudos em democracias representativas de massas, já que é característica típica destes regimes. Porém, o recente interesse em abordar empiricamente o Senado brasileiro em períodos mais afastados (NEIVA e IZUMI, 2014; MASSIMO e COSTA, 2014) revelou o desconhecimento de elementos que poderiam colaborar para o entendimento de sua evolução histórica.

Leite (1978), em um dos poucos trabalhos que se focam no Senado imperial, trata apenas os anos 1870-89. Ademais, é um trabalho com as preocupações do campo da História, não preocupada com teorias e métodos reconhecidos pela Ciência Política contemporânea. Isso, naturalmente, não nos impede de estabelecer um dialogo com trabalhos desta área, muito menos de tomarmos estes conhecimentos como hipóteses.

Cabe esclarecer que, ao abordar o tema para este período estamos cientes das críticas referentes a anacronismo, pois, ainda que a bibliografia histórica a qual nos filiamos aponte para relativa autonomia da política frente a outros âmbitos sociais, logo, para um ambiente institucional propício a formação de uma classe de políticos profissionais, a maior parte dos historiadores não o considera. Ainda que a profissionalização política tenha surgido em monarquias absolutistas europeias, não era uma característica marcante, apenas um fenômeno incipiente (WEBER, 1985).

Especificamente, nos antecipamos a duas críticas: a primeira é o fato de que estes políticos eram notáveis que atuavam em diversas atividades, sendo a política mais uma delas. O que dificultaria a aplicação da noção atualizada de política profissional.

Mas, o que não devemos esquecer, é que na definição clássica, político profissional não é apenas aquele que vive da política, no sentido de retirar sua renda exclusivamente da atividade, mas também aquele que vive para a política, ou seja, sem interesse material (devo acrescentar: de modo direto). Outro ponto, é que a teoria clássica considera que ser prescindível da ocupação de origem, e, principalmente ser independente financeiramente são as melhores condições para aquele que pretende tomar a política como atividade principal.

Assim, o estudo analisa em que medida os senadores imperiais se aproximam ou distam dos tipos ideias de políticos profissionais; já que, não necessariamente, coincidem com casos concretos, de modo, que a constatação de aspectos de uma política profissional fora de seu contexto típico, não significa que havia profissionalização em absoluto, e tampouco, deve ser visto como uma aberração. Trata-se, simplesmente, de um estado transitório entre uma política de tipo tradicional e outra moderna.

Como ficará claro na seção teórica, para testar o conceito de profissionalização que adotamos - entendida como a ambição do indivíduo em permanecer no campo político - basta medir variáveis referente à ocupação de cargos na estrutura política do Estado, prévios à entrada do político no Senado, o que chamamos de carreira política; considerada por muitos parte do processo de recrutamento para cargos políticos (PREWITT, 1970). Praticamente toda a literatura conhecida que aborda o Senado imperial, majoritariamente trabalhos de História, e apenas dois estudos de recrutamento, considera a experiência em cargos um dos critérios mais importantes para se aceder ao cargo, mas nenhum estudo se focou nesta afirmação, e menos, buscou comprovar empiricamente (FAORO, 1958; CARVALHO, 2003; LEITE, 1978; NEIVA e IZUMI, 2014).

Sumarizando a relação entre profissionalização, carreira e recrutamento, entendemos que uma alta incidência de carreiras prévias com pouca experiência, demonstraria que o recrutamento era mais relacionado com a tradição e o "familismo". Neste caso, o fator decisivo seria o pertencimento do recrutado ao séquito imperial - como sugerem as abordagens históricas hegemônicas. Ou seja, um critério externo à política. Em relação ao sistema político, isso sugeriria que o ambiente era nada autônomo, sendo determinado por outros 
âmbitos sociais, deste modo, extremamente personalista e patrimonialista.

Por outro lado, se constatado que uma carreira profissionalizada, entendida em termos de grande experiência em cargos políticos, era característica difundida no grupo, entenderíamos ser um recrutamento pautado também na valorização deste atributo. Sendo assim, entenderíamos que havia um considerável nível de institucionalização e autonomia relativa da política frente a outros âmbitos da vida social. E também que o cargo era pouco acessível a políticos novatos, ou ocasionais.

Sobre senadores terem relações com o séquito imperial, por mais que fosse comum (FAORO, 1958; LEITE, 1978), entendemos que não era atributo suficiente para aceder ao cargo, tampouco era requisito necessário.

Lembremos que os títulos nobiliárquicos, motivo levantado na literatura para demonstrar a proximidade da elite parlamentar com a nobreza, na monarquia brasileira, nem mesmo eram hereditários. O que não descarta sua importância como fator de distinção do status social, mas, nos induz a desconfiar de que era um capital que por si e sozinho podia ser convertido em capital político, menos para se alcançar o posto de senador, considerado um cargo culminante da carreira política da época pela maior parte da literatura (FAORO, 1958, LEITE, 1978, NEIVA e IZUMI, 2014; MASSIMO e COSTA 2014).

Inclusive, Neiva e Izumi (2014) nos mostram que os títulos nobiliárquicos foram na maioria das vezes cedidos a senadores quando estes já ocupavam o cargo. Neste sentido, é mais plausível pensar que era consequência de uma carreira política bem sucedida, tendo como uma de suas expressões mais importantes ser senador.

A despeito da importância conferida pela historiografia, como critério para o recrutamento a carreira política acaba ficando subsumida frente a critérios personalistas. Ademais, por não ser uma democracia representativa de massas, nos pareceu prudente elaborar a hipótese entendendo que a política imperial no Brasil estava mais próxima do modelo das monarquias absolutistas europeias. Portanto, esperamos um baixo nível de profissionalização entre os senadores, assim o cargo de senador deve haver sido facilmente permeável a novatos e políticos ocasionais.

Por ser um grupo do passado e dispormos de dados de carreira confiáveis nos apoiamos no método prosopográfico definido por Stone (2011) como a investigação de características comuns de indivíduos componentes de um grupo por meio do estudo coletivo de suas biografias, em variáveis como: nascimento e morte, casamento e família, origens sociais, educação, ocupação, religião, carreira política, etc. Além das corelações entre estas outras variáveis externas.

Massimo e Costa (2014) são importante referência para nosso estudo ${ }^{3}$. Pois, ainda que o interesse desta pesquisa não seja fazer uma comparação entre o Brasil imperial e a Primeira República, este trabalho pode ser consultado como parâmetro de alguns dos dados que apresentamos. Principalmente os critérios usados na variável tipo de carreira.

Descrevemos estatisticamente dados do universo de 236 indivíduos que foram nomeados ao Senado da $1^{\text {a }}$ legislatura (1826-1829) até a 20a (1886-1889). Nossa fonte principal são as fichas biográficas dos senadores imperiais produzidas pelo PRODASEN (Secretaria de Tecnologia da Informação do Senado Federal), órgão responsável pelo arquivo do Senado. Na planilha de dados, dispomos os cargos políticos em ordem ${ }^{3}$ Em Aumentando o campo para jogar: circulação política entre Senadores brasileiros durante a Primeira República é verificado se existe relação entre o advento da república e os padrões de carreira prévia dos senadores da $21^{\mathrm{a}}$ legislatura até a $37^{\mathrm{a}}$. Uma de suas principais conclusões é que as carreiras políticas na mesma medida em que se tornaram mais longas ao longo do período, também se diversificaram em termos de cargos, e esse comportamento é interpretado no sentido da profissionalização política, tanto dos atores políticos, como do parlamento. Baseados em Leite (1978), os autores nos demonstram ainda, que em termos de carreira política a transição do Brasil Império para a Primeira República é marcada mais por continuidades do que rupturas. 
cronológica, onde cada linha contém os postos ocupados até a chegada do indivíduo ao mandato de senador.

$\mathrm{O}$ artigo está dividido em cinco partes. Na primeira, apresentamos o marco teórico de profissionalização política. Na segunda, de modo sucinto, apresentamos aspectos contextuais relevantes para esta investigação, já que trazem a discussão da existência ou não de autonomia do âmbito político. Na sequência, de modo básico, descrevemos a estrutura de oportunidades de cargos no período, e como se inseria o Senado no sistema político do Brasil imperial. Dissertamos, de modo geral, também sobre o funcionamento e recrutamento do cargo. Na quarta parte, apresentamos os dados e suas respectivas análises. Por último, nas considerações finais, discutimos os achados à luz da bibliografia mobilizada. Para, por fim, concluirmos.

\section{PROFISSIONALIZAÇÃO POLÍTICA}

Para Weber, no início de sua existência, políticos profissionais foram homens a serviço de monarcas absolutistas, que expropriaram atores privados de meios de organização política. A consolidação deste processo foi o monopólio por parte do Estado, dos meios políticos. Diferente do tipo ideal do dirigente carismático weberiano, o tipo profissional não desejava ser "senhor", para ele, a atividade política podia ser tanto uma atividade rentável, como um meio de vida idealmente satisfatório (WEBER, 1985; pp. 15-17).

Perissinotto e Veiga (2012) nos apontam que a profissionalização política é produto da consolidação das democracias representativas. Estes autores partem da noção de Czdunowski (1975), e diferenciam três tipos ideais: 1- O político ocasional; 2- Aquele que tem a política como segunda profissão; e 3-Aquele que tem na política sua profissão principal.

Nos defrontamos com a dificuldade de estabelecer a profissão principal, já que o período imperial, por suas limitações à cidadania, fazia com que os indivíduos elegíveis a cargos políticos, principalmente o Senado, tivessem muitas oportunidade de obtenção de renda, o que fazia com que se ocupassem de variadas atividades econômicas ao mesmo tempo (DOLHNIKOFF, 2011). Além disso, compromete qualquer possibilidade de pensarmos em termos de terem estes políticos suas rendas tiradas exclusivamente da política. Mas não descarta a possibilidade da análise do regime de dedicação à política.

Apoiamo-nos na tradição de estudos que desenvolve nos termos da teoria da escolha racional esta noção de profissionalização. Em modelos que remontam à Schlesinger (1966), propositor da teoria da ambição política.

Black (1970) nos ensina que a profissionalização deve ser definida como em qualquer outro ramo de atividade econômica, caracterizada pela aderência por parte do agente, dos valores prevalentes no campo, de modo, que estes valores passam a pautar sua ação neste meio. Os valores podem variar dependendo de cada ramo de atuação, e também em tempo e lugar. Mas existiria um fator unívoco para distinção entre políticos amadores e profissionais: o grau de ambição que um e outro tem em adotar os valores do grupo profissional. Isso se sobreporia até mesmo em meios onde há um padrão homogêneo de socialização prévia.

A ambição pode ser medida pela aderência ao valor mais característico da política como campo de atuação profissional: a postura positiva do indivíduo frente ao ato de barganhar. Por consequência, isso faria com que profissionais tendam a adotar uma posição positiva também referente a trocar de um cargo político a outro.

Adotaremos parte do procedimento aplicado por Oliveira (2009), pois nem todas as variáveis usadas pela autora podem ser aplicadas para nosso caso. O modelo é baseado em Pedersen (1977) e comporta quatro indicadores: 1- Permeabilidade; 2-Volatilidade; 3- Continuidade; 4- Segurança na carreira. 
Volatilidade diz respeito à renovação no Senado, mas por haver sido o cargo de senador vitalício, não faz sentido, já que eleições eram realizadas, via de regra, para substituir um senador que falecia. Excluindo casos residuais, que não passam de seis em todo o Império, de políticos que foram afastados ou pediram licença do cargo. Continuidade também não faz sentido para o Senado imperial, também pelo motivo da vitaliciedade do cargo, já que o conceito procura captar se o cargo era ou não, visto como um posto transitório. Segundo a literatura, ainda que pudesse não ser o único ponto final de uma carreira, era com certeza um deles. Esse mesmo motivo invalida o conceito da segurança na carreira, que basicamente procura medir aqueles políticos que se aposentaram no cargo.

Relacionando as proposições de Oliveira (2010) com as dimensões usadas em Oliveira (2009), entendemos que a Permeabilidade do cargo pode ser analisada por meio da observação sistemática da carreira desses políticos. Revelando a dimensão institucional da profissionalização política, pois pode mostrar o grau de facilidade que um aspirante ao Senado Imperial tinha em aceder ao cargo. Toca também no aspecto individual, ou seja, a predominância de profissionais da política no cargo. Além disso, de certa maneira, fala do lado motivacional dos indivíduos - a ambição por cargos.

\section{A POLÍTICA NO BRASIL IMPERIAL}

A monarquia brasileira afastou-se ideologicamente do absolutismo. Inspirado na monarquia portuguesa de vertente liberal, e nas teses de Benjamin Constant, porém acrescentou aos Três Poderes de Montesquieu o Poder Moderador, que era, em tese, neutro e exercido pelo imperador por meio do Conselho de Estado ${ }^{4}$ (MARTINS, 2006; DOLHNIKOFF, 2011). Dolhnikoff (2011) mostra que no imaginário político o discurso era que se tratava de um governo representativo nos moldes das experiências inglesa e francesa.

Leite (1978) representa as teses tradicionais, que contrariam este imaginário. Onde a escravidão, a fraude eleitoral, o uso da violência, e o Poder Moderador são vistos como fatores que impediam o parlamentarismo e a representação de se concretizarem. Não havia autonomia dos poderes. A política se centrava exclusivamente na figura pessoal do Imperador, que nomeava os gabinetes sem compromisso com o parlamento, e podia dissolver a Câmara dos Deputados. Assim, a fraude eleitoral permitiria ao Imperador eleger uma nova Câmara composta por uma maioria pertencente ao partido no ministério e submissa a ele.

Além desta interpretação patrimonialista, temos outras duas visões extremistas: aqueles, como Faoro (1958), que entendiam a política submissa à burocracia, entendidas como um estamento, e aqueles que como Graham (1997), viram neste Estado o "comitê executivo" da classe dominante, ou seja, dos proprietários de terra.

A partir de Dolhnikoff (2011), entendemos que as características levantadas pela literatura para defender a ausência de representação e relativa autonomia tanto da política parlamentar, como dos outros poderes são equivocadas, já que estavam todos de acordo com o imaginário político da época, mesmo em países centrais, como Inglaterra e França.

Projetos de lei poderiam partir tanto das casas legislativas, quanto do Executivo. Neste último caso, o projeto era enviado para a Câmara, quando aprovado era mandado ao Senado, que podia aprovar, rejeitar ou emendá-lo. Se aprovado, tinha de ser sancionado pelo Imperador. Quando rejeitado era abandonado, se emendado, era novamente debatido e votado em sessão conjunta da Câmara e do Senado.

Sobre o Poder Moderador, o Imperador só podia dissolver a Câmara quando requisitado pelo ministério,

4 Para uma análise do Conselho de Estado e sua posição no sistema político imperial ver Martins (2006). 
havia a opção também de demitir os ministros. Diante de temas polêmicos, tudo isso era visto como um meio lícito, e um modo de consulta democrática, já que a decisão iria depender do posicionamento dos que ingressavam no pleito seguinte.

As qualificações para participar da política como votante, eram: ser homem, branco, ter mais de 25 anos, e apenas no fim do período, capacidade intelectual. Foi apenas em 1881 que se tornou restrição. Isso se explica pelo elevado número de analfabetos, inclusive entre membros importantes da elite econômica.

O critério da renda durou todo o Império; o exigido era 100 mil réis anuais para votar em primeiro grau, ou seja, em eleitores e também para se candidatarem a cargos eletivos, e 200 mil réis para ser eleitor em segundo grau: escolher os políticos diretamente. Trabalhadores de ofícios relativamente modestos, ainda que não tivessem condições reais de se elegerem, recebiam mais que o mínimo para votar.

O escravo estava fora da sociedade civil, logo não era membro da sociedade política. Os libertos tinham direito de voto mas não podiam ser eleitores, e menos candidatos. Os homens libertos eram considerados mais aptos que mulheres, mesmo branca e pertencente à elite, já que mulher alguma votava. Em geral, as restrições se baseavam na crença de que para que houvesse uma representação de qualidade era necessário que o eleitorado pudesse escolher livremente (DOLHNIKOFF, 2011).

Carvalho (2003) estuda a elite imperial para explicar a unidade da colônia americana portuguesa em detrimento à fragmentação da espanhola. Elite é definida a partir do critério posicional e compreende os seguintes grupos: ministros, senadores, deputados gerais e conselheiros de estado. São abordadas as variáveis: educação, ocupação e carreira.

O perfil dos políticos não representava o da população geral. Praticamente todos os seus membros possuíam curso superior, ao contrário da população. A formação em Direito na Universidade de Coimbra, destino comum da elite econômica e social brasileira, mais do que a socialização, teria contribuído decisivamente para a coesão ideológica da elite, fator determinante para a unificação do território. Deste modo, se desenvolveram como uma classe essencialmente política e com um projeto de Estado bem delineado.

Dolhnikoff (2003 e 2005), Vargas (2011) e Graham (1997) sugerem que as elites políticas regionais são relevantes para explicar a formação do Senado imperial, o que nos parece coerente com a realidade de um Estado que ainda carecia de alcance territorial.

Carvalho, quando trata da "dialética da ambiguidade" mostra como a elite política tinha que, "gostando ou não" compactuar com os proprietários de terra, para que houvesse pelo menos uma aparência de ordem (Carvalho, 2003: 232), isso supõe que havia grande influência de atores econômicos regionais, porém, em sua visão isso se dava diretamente com o centro do Império.

Para Graham (1997), a centralização do sistema político foi apoiado por fazendeiros, que no período anterior defendiam a autonomia local, para evitar que o movimento federalista desse início ao questionamento das bases do sistema de dominação. O fluxo do poder se dava do centro à localidade e vice-versa. Do centro através do presidente provincial, e do local ao presidente provincial, daí, até o centro. Os chefes locais detinham sempre o poder de eleger deputados. Dolhnikoff (2005), aponta que um maior alcance do Estado pelo território era um ideal que além de unir liberais e conservadores, mobilizava as elites provinciais. O legislativo provincial detinha amplos poderes, enquanto os poderes municipais se ocupavam apenas de assuntos administrativos.

Vargas (2011) mostra que a cúpula do governo imperial era formada por membros de famílias dos mais longínquos municípios. Conclui que as escolhas nas carreiras profissionais, estratégias políticas, nobilitação, visão de mundo, entre outros aspectos sociais, dependiam das redes estabelecidas no âmbito familiar. 
Graham (1997) entende que o clientelismo, visto como o sistema de práticas que conferia sentido social à atividade política por meio das hierarquias sociais formava um sistema de controle mútuo entre os detentores de recursos 5 .

Na mesma direção de outros autores aqui citados, como Dolhnikoff, Martins, e Leite, por exemplo, Graham nos diz que os cidadãos se dividiam politicamente não por causa de lealdades partidárias, e tampouco por ideologias, mas sim por laços pessoais. Disputas de poder local se davam entre facções reivindicando o pertencimento ao partido no poder. Haveria uma diferença na base social dos partidos, mas era insignificante. As relações de poder se davam em torno da fazenda (GRAHAM, 1997, p. 231).

O tema da institucionalização dos partidos é importante para o estudo da profissionalização política. Trabalhos recentes mostram que o processo começa nas agremiações ${ }^{6}$. Inclusive, pode haver profissionais que vivem apenas da política partidária. A visão de Carvalho (2003) sugere diferença entre os partidos políticos e certa autonomia frente a interesses econômicos. O que não quer dizer, é claro, que se tratassem de partidos institucionalizados, segundo Carvalho, pelo contrário. Para se ter uma ideia, até 1837 não existiam, e apenas em 1864 foi elaborado o primeiro programa partidário. Daí vem nosso desinteresse em analisar a profissionalização dentro dos partidos imperiais.

A partir do marxismo, Graham entende que o fato dos cargos da burocracia serem ocupados por membros da classe dominante mostraria que sua função era vincular tal classe ao governo e não agir independentemente dela.

Carvalho (2003) reconhece na burocracia um caminho inevitável para os letrados e também para os setores médios urbanos. As limitadas ocupações para estes indivíduos em uma sociedade basicamente agrária e escravocrata eram a causa desse fenômeno. Neste ponto, entendemos que a elite era um âmbito autônomo da organização socioeconômica, ainda que relacionado a ela (DOLHNIKOFF, 2005, p. 154).

A cúpula da burocracia se confundia com o Estado ${ }^{7}$. Por isso, na análise da carreira dos senadores consideraremos tais cargos. Seja nas instituições militares, civis ou eclesiásticas, um grupo de pouco mais que 350 pessoas eram fonte de recrutamento para a maior parte dos cargos políticos. Para Carvalho esta camada da burocracia se constituía como uma verdadeira elite política, que se constituía como uma instância de negociação com outros setores sociais.

O problema com a abordagem de Graham (1997) em detrimento a de Carvalho (2003) sobre como fluía o poder pelo sistema imperial, é que a noção de clientelismo implica troca entre atores de poder desigual, onde o Estado é a parte mais poderosa, distribui benefícios públicos a câmbio de qualquer tipo de apoio que precise. Para Carvalho, Graham indevidamente inverte o uso do conceito, fazendo com que o Estado apareça como clientela do senhoriato (FARIA, 2013, p. 11).

\footnotetext{
${ }^{5}$ É preciso, neste ponto, dizer que práticas familiares e clientelísticas não estão em desacordo com a noção de profissionalização política.
}

${ }^{7}$ Para Carvalho (2003) esta não é uma característica apenas deste sistema econômico, seria comum a todas as experiências em que houve capitalismo retardatário ou frustrado. Porém, o autor se distancia de visões que atribuíam uma importância exacerbada à burocracia na administração, como é o caso de Faoro, que a via como um estamento, em torno do qual orbitava todas as instituições. Ao mesmo tempo, discorda de que era totalmente subordinada aos proprietários rurais. 
4. O CARGO DE SENADOR E SUA POSIÇÃO NA ESTRUTURA DE CARGOS

Dos cargos que, segundo Carvalho (2003), compunha a elite política imperial (ministros, senadores, deputados gerais e conselheiros de Estado) apenas o cargo de deputado era escolhido de modo puramente eletivo. Porém não e com renda de mais de 100 mil réis por ano. Para ser eleitor, a renda mínima era 200 mil réis ao ano. Ministros e conselheiros de Estado eram nomeados direta e unicamente pelo Imperador.

No âmbito do executivo imperial a partir de 1847 passou a existir o cargo de Primeiro-ministro (presidente do Conselho de Ministros) que também era nomeado pelo monarca.

Nas Províncias até 1834, quando do Ato Adicional vigorava a total dependência do governo central, o único cargo era o de conselheiro geral de província, cargo legislativo nomeado pelo Imperador. A partir de então criou-se no lugar destes conselhos as assembleias provinciais, cargo eletivo, em que se votava em dois graus. Além disso, foi criado o poder executivo provincial centrado na figura do presidente de província, cargo de nomeação por parte do monarca.

No âmbito da localidade havia dois cargos eletivos relevantes: juiz de paz, um cargo jurídico, mas com forte componente político e vereador. Não havia prefeitos, e sim um Conselho de vereadores presidido pelo vereador que tivesse maior número de votos. Apenas em 1834 que São Paulo e algumas províncias do nordeste instituíram o cargo.

O Senado no Brasil Império foi inspirado na Câmara dos Lordes da Inglaterra e na Câmara dos Pares da França. Aqui adquiriu um caráter mais "democrático". O número de senadores não podia ser alterado pelo Imperador. A bancada de cada província era composta por metade do número de deputados da mesma província e este número só mudava com aprovação da maioria da Câmara respeitando o critério de proporção populacional. Enquanto em países como França e Portugal, o monarca podia garantir maioria parlamentar através da criação e nomeação de novas cadeiras. Mesmo assim, por carecer de eleições periódicas, para Dolhnikoff (2011) não era um órgão representativo.

Leite (1978) pensa que fatores externos os diferenciavam dos senados europeus, principalmente o poder moderador e a vitaliciedade do cargo, sendo assim uma instituição da Coroa ligada aos seus interesses. Era o órgão legislativo com maior força na época, incorporava a elite econômica e cultural do país. A vitaliciedade impedia dissoluções e não permitia que fosse composto segundo interesses momentâneos ${ }^{8}$.

Quando vagava uma cadeira, no prazo de três meses ocorria uma eleição. Assim, o presidente da província, quem "controlava" a vaga, era avisado pelo presidente do Senado, ou outro membro do governo para realizar eleições. Os três nomes mais votados eram enviados ao monarca para que esse escolhesse. Daí, o nome era apresentado ao Senado para que fosse aprovado ou não, nesta instância verificava-se a ausência de fraudes para confirmar a legitimidade da eleição. Para tomar posse, o eleito tinha que receber sua Carta Imperial, e direcioná-la ao Presidente do Senado, que encaminhava a uma comissão encarregada de examinar a legalidade do diploma. Por fim, se prestava um juramento à Constituição, à religião católica e de que se iria sustentar a indivisibilidade do Império.

O salário no período estudado por Leite (1970-1989) era de 9 contos de réis por ano. A maioria dos senadores possuía títulos universitários. $\mathrm{O}$ candidato ao cargo deveria ter mais de quarenta anos, renda maior a oitocentos mil réis anuais oriunda da indústria, comércio ou emprego. Geralmente os senadores eram pro-

\footnotetext{
${ }^{8}$ Neiva e Izumi (2014) fizeram um estudo de longo alcance temporal, onde procuraram mapear os perfis profissionais dos senadores brasileiros, da primeira legislatura em 1826 até 2010. Apesar de suas conclusões não se focarem no período imperial trazem informações que complementam a discussão.
} 
prietários rurais, ou ligados à elite da terra por meio de parentesco ou matrimônio. Era notória a quantidade daqueles que possuíam títulos nobiliárquicos (Neiva e Izumi, 2014; Leite, 1978). A passagem por importantes cargos da época, como Deputado, Presidente de Província, Ministro, Diplomata e Conselheiro de Estado era fundamental para o recrutamento. Leite diz que eram homens que possuíam altos rendimentos, representantes dos interesses provinciais, e das oligarquias, e que apesar de estarem ligados aos partidos, atuavam muitas vezes em discordância com as agremiações.

\section{A CARREIRA POLÍTICA DOS SENADORES NO BRASIL IMPÉRIO}

O Quadro 1 mostra todos os cargos encontrados em nossa fonte em ordem alfabética. Optamos por este modo, pois organizá-los por área é bastante complicado, não só pela grande fragmentação, mas também pelo desconhecimento da natureza do cargo. Fizemos o possível para evitar que houvesse nomes duplicados, porém, para evitar a perca de dados optamos por respeitar a nomenclatura encontrada na fonte ao máximo, o que pode ter feito com que alguns cargos sejam especificações de outros que estão contemplados com o título mais genérico.

Quadro 1 - Cargos considerados na carreira prévia dos senadores 


\begin{tabular}{|c|c|c|c|}
\hline Administrador dos Direitos de & Diretor da 'Gazeta Oficial' do Império & Juiz dos Feitos da Fazenda Nacional & Oficial-Maior da Secretaria de Estado \\
\hline Exportação & Diretor da Repartição de Estatística & Juiz Especial do Comércio & dos Negócios do Reino \\
\hline Advogado do Conselho do Estado & Diretor de Instrução Pública do Ceará & Juiz Municipal de Órfäos do Termo & Ouvidor \\
\hline Almirante de Esquadra & Diretor de Seção da Secretaria da & Juiz Municipal e de Órfãos & Ouvidor da Comarca \\
\hline Auditor da Guerra & Justiça & Juiz Relator do Conselho Supremo & Ouvidor da Provincia \\
\hline Auditor das Tropas da Corte e da & Diretor do Banco do Brasil & Militar & Ouvidor do Crime \\
\hline Provincia & Diretor-geral das Terras Públicas & Lente de Medicina da Faculdade de & Prefeito \\
\hline Auditor Geral da Marinha & Diretor-geral do Tesouro & Medicina da Corte & Presidente da Junta Governativa \\
\hline Auditor-geral das Tropas do Exército & Embaixador & Médico da Câmara Imperial & Presidente da Mesa do Desembargo do \\
\hline Catedrático da Academia Militar & Fiscal e Superintendente da Junta & Imperador & Presidente da Relação da Corte \\
\hline Censor Régio da Imprensa & Fiscal Interino da Junta dos Arsenais, & Membro da Comissão de Liquidação & Presidente de Provincia \\
\hline Chanceler da Relação & Fábricas e Fundições & do Primeiro Banco do Brasil & Presidente do Banco do Brasil \\
\hline Chanceler e Regedor da Casa de & Governador das Armas da Corte & Membro da Junta do Governo & Presidente do Conselho de Ministros \\
\hline Suplicação & Governador das Armas da Província & Membro da Primeira Junta do Governo & Presidente do Imperial Instituto \\
\hline Chefe da Seção da Secretaria dos & Inspetor da Alfândega na Corte & Provisório da Provincia & Sergipano de Agricultura \\
\hline Negócios do Império & Inspetor da Casa de Fundição & Membro da Primeira Junta & Presidente do Montepio Agricola \\
\hline Chefe de Policia da Corte do Império & Inspetor da Fábrica de Pólvora da & Governativa Provisória & Presidente do Montepio de Economia \\
\hline Comandante da Guarda Nacional & Inspetor da Fazenda & Membro do Conselho Administrativo & Presidente do Primeiro Conselho Geral \\
\hline Comandante de Regimento de Linha & Inspetor da Tesouraria Geral & da Pro & da Província \\
\hline Comandante Superior da Guarda & Inspetor da Tesouraria Provincial & Membro do Conselho Diretor da & Presidente do Tribunal de Contas da \\
\hline Nacional & Inspetor de Algodäo & Instrução Pública & União \\
\hline $\begin{array}{l}\text { Comissário do Governo Imperial Junto } \\
\text { ao Instituto dos Meninos Cegos }\end{array}$ & $\begin{array}{l}\text { Inspetor-geral da Caixa de } \\
\text { Amortização }\end{array}$ & $\begin{array}{l}\text { Membro do Conselho Geral da } \\
\text { Provincia }\end{array}$ & $\begin{array}{l}\text { Presidente do Tribunal de Relação } \\
\text { Primeiro Juiz da Comarca }\end{array}$ \\
\hline Conselheiro da Fazenda & Intendente da Marinha & Membco honorárig da British and & Procurador da Coroa \\
\hline Conselheiro de D. Pedro II & Intendente do Ouro da Corte & Eoreing anti-slavery society, de & Procurador dos Feitos da Fazenda \\
\hline Conselheiro de Estado & Intendente do Ouro Provincial & Lendres. & Procurador Fiscal da Fazenda Nacional \\
\hline Conselheiro de Estado Honorário & Intendente dos Diamantes & Adjunto do Conselho do & Procurador Fiscal da Tesouraria da \\
\hline Conselheiro de Guerra & Intendente Geral da Polícia & Supremo Tribunal Militar & Fazenda \\
\hline Conselheiro do Erário Régio & Intendente-geral das Minas & Ministro Agricultura, Comércio e Obras & sProcurador \\
\hline Consultor do Ministério do Império & Juiz Conservador da Companhia de & & \\
\hline Contador Geral do Tesouro & Vinhos do Alto Douro & Ministro da Agricultura & Procurador Fiscal do Tesouro do \\
\hline Coronel da Guarda Nacional & Juiz Conservador da Nação Inglesa & Ministro da Agricultura, Fábricas e & Império \\
\hline Corregedor da llha da Madeira & Juiz Conservador dos Ingleses & Navegação & Procurador-geral da Provincia \\
\hline Curador-geral dos Órfãos & Juiz da Primeira Vara Cível & Ministro da Justiça & Promotor Público \\
\hline Delegado de Policia & Juiz da Primeira Vara do Crime da & tro da Marinha & Provedor da Fazenda, dos Defuntose \\
\hline Deputado às Cortes Portuguesas & Corte & Ministro das Relações Exteriores & Ausentes, Resíduos e Capelas \\
\hline Deputado da Real Junta do Comércio & Juiz das Sesm & tado & Provedor da Santa Casa de \\
\hline Deputado de Agricultura da Mesa de & Juiz de Alfândegas do Rio Grande do & Ministro do império & Misericórdia \\
\hline Inspeçäo & Sul e de Santa Catarina & Ministro do Império dos Negócios & Provedor de Saúde da Província \\
\hline Deputado Geral & Juiz de Direito & Estrangeiros & Regente \\
\hline Deputado Provincial & Juiz de Direito da Câmara & Ministro do Supremo Tribunal de & Servidor Público \\
\hline Desembargador da Casa da Suplicação & Juiz de Direito da Comarca & Justiça & Substituto do Juiz de Direito Municipal \\
\hline Desembargador da Casa da Suplicaçäo & Juiz de Direito da Segunda Vara do & Ministro do Supremo Tribunal Militar & Superintendente Geral dos \\
\hline Fiscal do Erário Régio & Crime & Ministro dos Estrangeiros & Contrabandos \\
\hline Desembargador da Mesa da & Juiz de Direite & Ministro dos Negócios da Justiça & Suplente de Juiz de Paz \\
\hline Consciência & Juiz de Direito Substituto & Ministro dos Negócios do Império do & Suplente do Conselho Geral da \\
\hline Desembargador da Província & Juiz de Feitos da Fazenda & Brasil & Provincia \\
\hline Desembargador da Relação & Juiz de Fora da Câmara & Ministro dos Negócios Estrangeiros & Tesoureiro da Real Imprensa \\
\hline Desembargador do Paço & Juiz de Fora da Comarca & Ministro Plenipotenciário & Tesoureiro do Tribunal do Arsenal do \\
\hline Desembargador Geral da Educação & Juiz de Fora da Corte & Oficial da Secretaria de Estado dos & Exército \\
\hline Primária e Secundária da Corte & Juiz de Fora do Termo & Negócios do Reino & Tesoureiro Pagador Das Tropas \\
\hline Diplomata & Juiz de Órfäos & Exército (general Brigadei & \\
\hline Diretor da Alfândega & Juiz de Paz & Oficial de Gabinete do Ministro da & Viador da Casa Imperial \\
\hline Diretor da Cia. Brasileira Jorrens. & Juiz de Vara da Vila & Marinha do Sexto Gabinete do & Vice-presidente de Provincia \\
\hline Diretor da Estrada de Ferro D. Pedro II & Juiz do Civil & Segundo & Vice-presidente do Tribunal do \\
\hline $\begin{array}{l}\text { Diretor da Faculdade de Medicina da } \\
\text { Corte }\end{array}$ & Juiz do Crime da Corte & Oficial de gabinete do Presidente da & Tesouro \\
\hline
\end{tabular}

Fonte: Observatório de elites políticas e sociais do Brasil (Nusp / UFPR). 
A Tabela 1 mostra o tempo médio de carreira, enquanto a Tabela 2, a quantidade de cargos prévios ao Senado por geração de ingresso. Para criar parâmetros temporais de análise, separamos os senadores por geração de ingresso ao Senado, pois esperamos um incremento na média de tempo de carreira e número de cargos ocupados anteriores ao Senado, pela simples passagem do tempo, que teoricamente influenciou na institucionalização do sistema imperial e na consolidação da estrutura de oportunidades de cargos políticos. Assim, não se espera, por exemplo, que os parlamentares da primeira legislatura tenham grande experiência, já que o sistema político estava recém-inaugurado.

Para que uma separação em gerações fizesse sentido, visto que os pleitos não tinham um tempo preestabelecido, e sendo o cargo vitalício, a entrada de uma nova legislatura não significava a renovação de um número fixo de senadores. Isolamos a Legislatura 1 como sendo a Geração 1 (1826-1829), inaugurada com 50 senadores. Nas outras legislaturas, buscamos separar o mais próximo possível de intervalos contados em décadas, garantindo um $\mathrm{N}$ considerável em cada um delas. Como resultado, temos a seguinte divisão: Geração 2 (Legislaturas 2 a 4 (1830-41)); Geração 3 (Legislaturas 5 a 8 (1843-52)); Geração 4 (Legislaturas 9 a 12 (185366)); Geração 5 (Legislaturas 13 a 16 (1867-78)); e Geração 6 (Legislaturas 17 a 20 (1878-89)).

Tabela 1 - Tempo de carreira prévia ao Senado por geração de ingresso ao cargo

\begin{tabular}{|c|c|c|c|c|}
\hline Geração de ingresso ao Senado & Média & Mediana & Desvio Padrão & $\mathbf{N}$ \\
\hline Leg. $1 \quad(1826-29)$ & 12,84 & 7 & 20,08 & 42 \\
\hline Legs. 2 a 4 (1830-41) & 10,13 & 13 & 20,04 & 26 \\
\hline Legs. 5 a 8 (1843-52) & 12,34 & 17 & 24,45 & 30 \\
\hline Legs. 9 a $12(1853-66)$ & 11,37 & 17 & 22,41 & 26 \\
\hline Legs. 13 a 16 (1867-78) & 17,84 & 24 & 31,41 & 29 \\
\hline Legs. 17 a 20 (1878-89) & 17,13 & 22 & 28,90 & 30 \\
\hline
\end{tabular}

Fonte: Observatório de elites políticas e sociais do Brasil (Nusp / UFPR). 
Tabela 2 - Quantidade de cargos prévios ao Senado por geração de ingresso ao cargo

\begin{tabular}{|c|c|c|c|c|}
\hline Geração de ingresso ao Senado & Média & Mediana & Desvio Padrão & $\mathbf{N}$ \\
\hline Leg. $1 \quad(1826-29)$ & 10,52 & 4 & 9,91 & 50 \\
\hline Legs. 2 a 4 (1830-41) & 8,19 & 5 & 9,30 & 30 \\
\hline Legs. 5 a $8(1843-52)$ & 11,86 & 8 & 8,33 & 33 \\
\hline Legs. 9 a $12(1853-66)$ & 13,24 & 7 & 12,87 & 36 \\
\hline Legs. 13 a 16 (1867-78) & 13,05 & 8 & 10,24 & 33 \\
\hline Legs. 17 a 20 (1878-89) & 13,05 & 7 & 10,81 & 38 \\
\hline
\end{tabular}

Fonte: Observatório de elites políticas e sociais do Brasil (Nusp/UFPR).

Na primeira geração de senadores, a média de tempo de carreira política era de 12,84 anos e 10,52 cargos. Na segunda geração, os números diminuem para 10,13 anos de carreira e 8,19 cargos, voltando a subir na terceira, apresentando 12,34 anos e 11,86 cargos. Na quarta, volta a cair o tempo de carreira, mas notamos um aumento no número de cargos: 11,37 anos e 13,24 cargos. Nas duas últimas gerações, encontramos números maiores que os das 4 gerações anteriores: 17,84 anos na quinta geração e 17,13 na última; quanto ao número de cargos, ambos apresentaram o valor 13,05. Ainda que haja um incremento considerável quando comparamos a primeira e a última geração, o que mais nos chama atenção é que os senadores já na primeira legislatura apresentavam grande experiência. Diferente do esperado não foi encontrado um padrão ascendente proporcional à passagem do tempo.

No Gráfico 1, apresentamos os tipos de carreira relacionada à geração de ingresso no Senado. As carreiras foram categorizadas em oito tipos, com base no tempo de carreira, número de cargos, ambos prévios ao Senado, e ocupação de cargos em um ou mais níveis de poder (local; provincial; e imperial): 1- carreiras curtas, com poucos cargos e homogêneas: até cinco anos de experiência, com até cinco cargos ocupados em apenas um nível de governo; 2- carreiras curtas, com poucos cargos e heterogêneas: até cinco anos de experiência, com até cinco cargos ocupados em mais de um nível de governo; 3- carreiras curtas, com muitos cargos e homogêneas: até cinco anos de experiência, com mais de cinco cargos em apenas um nível de governo; 4carreiras curtas, com muitos cargos e heterogêneas: até cinco anos de experiência, com mais de cinco cargos em mais de um nível de governo; 5-carreiras longas, com poucos cargos e homogêneas: mais de cinco anos de experiência, com até cinco cargos ocupados em apenas um nível de governo; 6-carreiras longas, com poucos cargos e heterogêneas: mais de cinco anos de experiência, com até cinco cargos ocupados em mais de um nível de governo; 7- carreiras longas, com muitos cargos e homogêneas: mais de cinco anos de experiência, com mais de cinco cargos ocupados em apenas um nível de governo; e 8-carreiras longas, com muitos cargos e heterogêneas: mais de cinco anos de experiência, com mais de cinco cargos em mais de um nível de governo. 
Gráfico 1 - Tipos de carreira prévia por geração de ingresso no Senado imperial

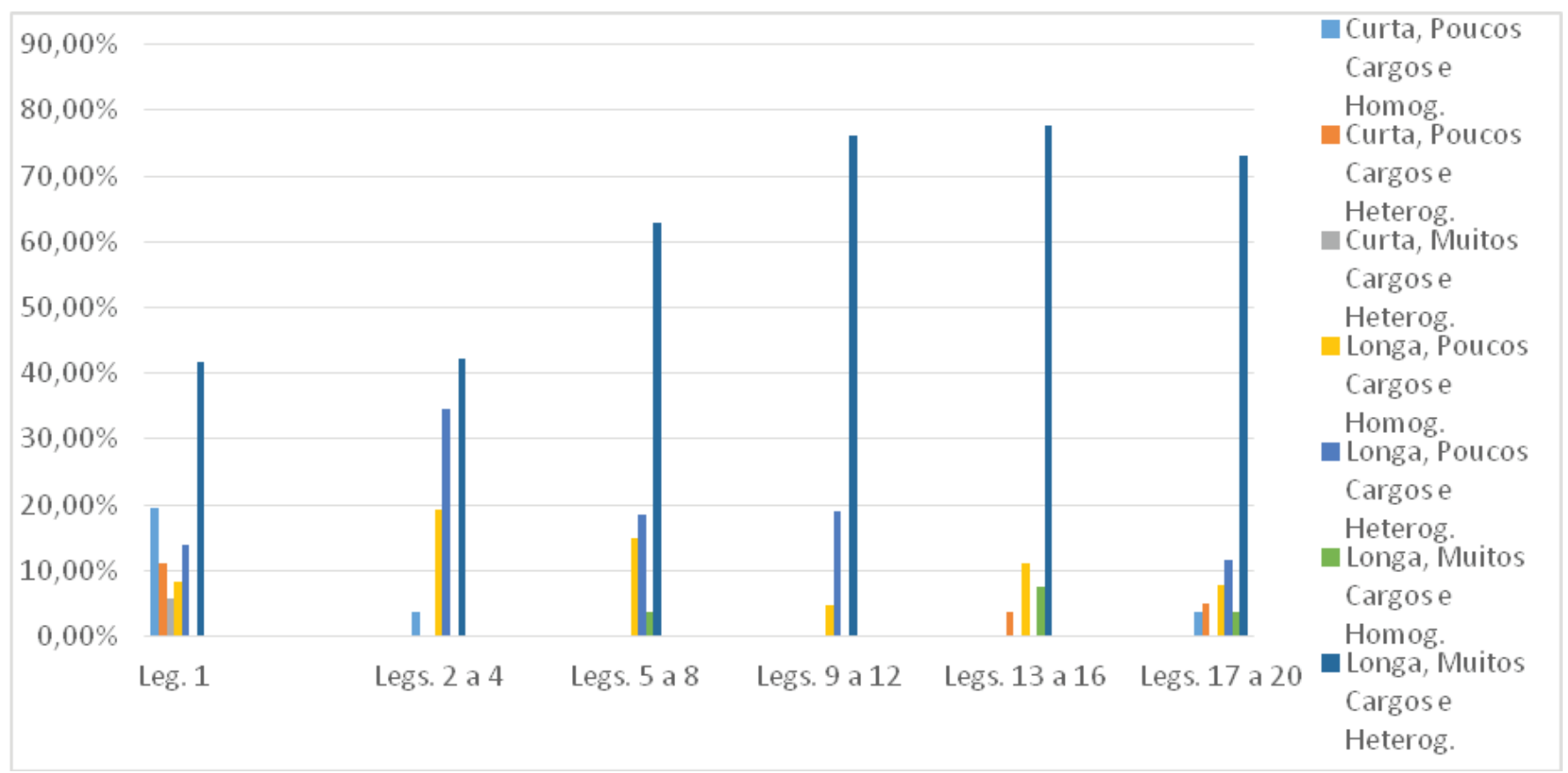

Fonte: Observatório de elites políticas e sociais do Brasil (Nusp/UFPR).

Apesar da grande fragmentação dos dados, o x² do cruzamento é de 60,126 (sig=0,001), ou seja, acima do limite crítico que é de 43,773. Isso indica haver associação entre as duas variáveis. Para os fins do teste de nossa hipótese, poderíamos considerar que todos os tipos de carreiras longas são profissionalizados. Em todas as gerações, exceto a primeira, carreiras longas representam mais de $90 \%$ do total.

Porém, para tornarmos as evidências mais significativas, consideremos apenas o grupo daqueles que possuíam carreira longa, com muitos cargos e heterogênea, ou seja, o tipo de carreira que denota maior experiência, e mais importante ambição política. Esta categoria representa 60,7 \% do total. Em todas as gerações é a categoria que concentra os maiores números, sendo: 41,7\% na primeira geração; $42,3 \%$ na segunda; $63 \%$ na terceira; $76,2 \%$ na quarta; $77,8 \%$ na quinta e $73,1 \%$ na última.

Os números demonstram também haver um incremento desta categoria quando se avançam as gerações, exceto por um pequeno decréscimo na última geração. Porém, não é gradual, o que nos induz a pensar não ser evidência suficiente que este aumento esteja ancorado na passagem do tempo como esperávamos. O que sim está claro, é que a única geração que apresenta valores significativos para carreiras curtas é a primeira geração, com os valores $19,4 \%$ para o tipo de carreira 1; 11,1\% para o tipo 2 e 5,6\% para o tipo 4 (o tipo 3 não está representado na distribuição, visto que é menos provável, por serem “carreiras curtas, com muitos cargos e homogênea". O decréscimo nas carreiras curtas tampouco varia com relação a passagem do tempo.

Apenas da primeira geração em relação às outras (que apresentam números baixíssimos, às vezes próximos a $0,0 \%$ ). O que nos induz a pensar que apenas na primeira legislatura, em que havia um nível mais baixo de institucionalização do regime, se admitia indivíduos inexperientes no cargo de senador. Percebemos pela a análise do resíduo padronizado que há associação entre ter carreira curta (de todos os tipos) e ser da primeira geração, o que não significa que neste grupo a maior parte dos indivíduos teve carreira curta, pelo contrário.

Nas Tabelas 3, 4, 5 e 6, buscamos medir quanto Senadores passaram pelos outros cargos apontados por Carvalho (2003), como sendo a elite do Império, antes de alcançarem o posto no Senado. Além disso, 
acrescentamos o cargo de presidente de província apontado por Leite (1958) como sendo parte comum das carreiras destes políticos.

Tabela 3 - Senadores que foram presidentes de província antes de chegarem ao Senado

\begin{tabular}{c|c|c}
\hline & N & $\%$ \\
\hline Não Foi presidente de província & 148 & 66,4 \\
Foi presidente de província & 75 & 33,6 \\
Total & 223 & 100 \\
\hline Missing & 13 & 5,5 \\
\hline Total Geral & 236 & \\
\hline
\end{tabular}

Fonte: Observatório de elites políticas e sociais do Brasil (Nusp/UFPR).

Podemos perceber que ser presidente de província era relativamente desimportante frente aos outros cargos que medimos nas carreiras dos senadores, a maioria (66,4 \%) não passava por este cargo. É interessante notar que o dado pode estar subdimensionado, pois o cargo foi criado apenas em 1834. Além disso, quando observamos as datas de entrada e saída destes políticos percebemos que duravam pouco tempo no exercício da função, geralmente de 3 a 5 meses, fator potencial do desinteresse de políticos prestigiosos.

Notamos também, que era comum um mesmo indivíduo transitar por diversas províncias ao longo de sua carreira, ocupando cargos em geral, e no caso daqueles que foram presidentes de província, a circulação pelo território era mais acentuada - o que denota grande empenho desses atores em suas atividades políticas. Consideremos que o deslocamento naquele período era algo bastante dispendioso.

Uma curiosidade, é que a $66,7 \%$ dos senadores depois de transitarem por todo o país terminou falecendo no Rio de Janeiro (a capital do Império e sede do Senado). Isso quer dizer que a posição de senador tendia em grande medida determinar a residência dos políticos até o fim da vida, mostrando que, ou esses políticos passavam a exercer suas profissões de origem nos locais por onde passavam, e por fim na capital, ou as deixavam de praticar em prol do exercício da política.

A Tabela 4, por sua vez, mostra quantos dos senadores foram deputados gerais antes do Senado.

Tabela 4 - Senadores que foram deputados gerais antes de chegarem ao Senado

\begin{tabular}{c|cc}
\hline & N & $\%$ \\
\hline Não foi deputado geral & 55 & 24,7 \\
\hline Foi deputado geral & 168 & 75,3 \\
\hline Total & 223 & 100,0 \\
\hline Missing & 13 & 5,5 \\
\hline Total Geral & 236 & \\
\hline
\end{tabular}

Fonte: Observatório de elites políticas e sociais do Brasil (Nusp/UFPR). 
Aqui é notória a importância do cargo de deputado geral na composição das carreiras. Apenas 24,7\% dos senadores não passaram ao menos em uma oportunidade pelo posto. É necessário salientar algumas coisas: eram comuns os casos daqueles que passavam muitas vezes pelo cargo ao longo de suas carreiras; deste valor temos que subtrair 9,5\% que são os casos daqueles que não tinham carreira prévia alguma. Ou seja, apenas $15,2 \%$ dos indivíduos não foram deputados antes de senadores.

Na Tabela 5, fizemos o mesmo procedimento, mas desta vez com os cargos em pastas ministeriais.

Tabela 5 - Senadores que foram ministros antes de chegarem ao Senado

\begin{tabular}{c|c|c}
\hline & N & $\%$ \\
\hline Não foi ministro & 145 & 65,0 \\
Foi ministro & 78 & 35,0 \\
\hline Total & 223 & 100,0 \\
\cline { 1 - 1 } Missing & 13 & 5,5 \\
\hline Total Geral & 236 & \\
\hline
\end{tabular}

Fonte: Observatório de elites políticas e sociais do Brasil (Nusp/UFPR).

Os resultados para o cargo de ministro são bastante distintos do de deputado: $35 \%$ dos senadores ocuparam este cargo, e aqui, é interessante falar que estes políticos ocupavam variadas pastas e/ou muitas vezes a mesma ao longo de suas carreiras.

No caso da Tabela 6, nos preocupamos não somente em medir a quantidade daqueles senadores que foram conselheiros de Estado, mas também se aqueles que ocuparam o cargo foram nomeados antes ou depois da nomeação para o Senado. Pelo motivo de que há uma divergência na literatura: Leite (1958), dentre outros, acreditam que o Senado era o cargo visto como mais importante na estrutura de oportunidades; por outro lado, Martins (2006) considera ser o Conselho de Estado. Ainda que não resolva a questão em definitivo podemos entender entre aqueles que ocuparam os dois cargos, qual veio antes.

Tabela 6 - Senadores que foram conselheiros de Estado

\begin{tabular}{|c|c|c|}
\hline & $\mathbf{N}$ & $\%$ \\
\hline Não foi conselheiro de Estado & \multirow{3}{*}{$\begin{array}{c}152 \\
33 \\
38\end{array}$} & \multirow{5}{*}{$\begin{array}{c}68,2 \\
14,8 \\
17,0 \\
100,0 \\
5,5\end{array}$} \\
\hline Conselheiro de Estado antes de senador & & \\
\hline Conselheiro de Estado depois de senador & & \\
\hline Total & \multirow{3}{*}{$\begin{array}{c}223 \\
13 \\
236\end{array}$} & \\
\hline Missing & & \\
\hline Total Geral & & \\
\hline
\end{tabular}

Fonte: Observatório de elites políticas e sociais do Brasil (Nusp/UFPR).

Dos senadores, 31,8 \% foram conselheiros de Estado, temos que fazer a ressalva de que o Conselho esteve extinto de 1834 a 1842, o que influencia nestes números. Destes, 14,8\% foram antes do Senado e 17\% depois - o que a princípio faz parecer que a ordem não importava, era aleatória. O cargo era composto apenas por dez membros, o que também incide nesta aparente baixa circulação entre os cargos. 
A Tabela 7 expõe o cargo imediatamente anterior à entrada no cargo por geração de ingresso ao Senado. A análise confirma a relevância do cargo de deputado geral para o acesso ao Senado, em todo o período representou $50,3 \%$ do total. Na penúltima geração, representou $71,9 \%$ do total. Sendo majoritário em todas as gerações.

Tabela 7 - Cargo imediatamente anterior ao Senado por geração de ingresso

\begin{tabular}{|c|c|c|c|c|c|c|c|c|}
\hline \multirow{2}{*}{\multicolumn{2}{|c|}{$\begin{array}{l}\text { Geração de } \\
\text { ingresso no } \\
\text { Senado }\end{array}$}} & \multicolumn{7}{|c|}{ Cargo imediatamente anterior ao Senado } \\
\hline & & \multirow{2}{*}{$\begin{array}{l}\text { Dep. } \\
\text { Geral } \\
14\end{array}$} & \multirow{2}{*}{$\begin{array}{c}\text { Ministro } \\
11\end{array}$} & \multirow{2}{*}{$\begin{array}{c}\text { Dep. } \\
\text { Provincial } \\
0\end{array}$} & \multirow{2}{*}{$\begin{array}{c}\text { Cargo na } \\
\text { diplomacia } \\
5\end{array}$} & \multirow{2}{*}{$\begin{array}{c}\text { Conselheiro de } \\
\text { Estado } \\
4\end{array}$} & \multirow{2}{*}{$\begin{array}{c}\text { Pres. de } \\
\text { Provincia } \\
9\end{array}$} & \multirow{2}{*}{$\begin{array}{r}\text { TOTAL } \\
43\end{array}$} \\
\hline Leg. 1 & $\mathbf{N}$ & & & & & & & \\
\hline & $\%$ & 32,6 & 25,6 & 0,0 & 11,6 & 9,3 & 20,9 & 100 \\
\hline $\begin{array}{l}\text { Legs. } 2 \text { a } 4 \\
(1830-41)\end{array}$ & $\%$ & 37,9 & 24,1 & 3,4 & 17,2 & 0,0 & 17,2 & 100 \\
\hline $\begin{array}{l}\text { Legs. } 5 \text { a } 8 \\
(1843-52)\end{array}$ & $\%$ & 46,7 & 20,0 & 3,3 & 3,3 & 10,0 & 16,7 & 100 \\
\hline $\begin{array}{l}\text { Legs. } 9 \text { a } 12 \\
\left(1853^{-66)}\right.\end{array}$ & $\%$ & 64,5 & 9,7 & 3,2 & 3,2 & 6,5 & 12,9 & 100 \\
\hline $\begin{array}{l}\text { Legs. } 13 \text { a } 16 \\
(1867-78)\end{array}$ & $\%$ & 53,3 & 10,0 & 3,3 & 0,0 & 20,0 & 13,3 & 100 \\
\hline $\begin{array}{l}\text { Legs. } 17 \text { a } 20 \\
(1878-89)\end{array}$ & $\%$ & 71,9 & 15,6 & 3,1 & 3,1 & 6,3 & 0,0 & 100 \\
\hline Total & $\%$ & 50,3 & 17,9 & 2,6 & 6,7 & 8,7 & 13,8 & 100 \\
\hline
\end{tabular}

Fonte: Observatório de elites políticas e sociais do Brasil (Nusp/UFPR).

\section{CONSIDERAÇÕES FINAIS}

Primeiramente, o principal achado da pesquisa é que quando comparados o fim e o início do período encontramos um incremento na experiência dos senadores, não só no que se refere à quantidade de cargos e tempo de carreira, mas também em termos de níveis de poder (local, provincial e imperial). Isso sugere que se é verdade a existência de coesão ideológica da elite, nos termos de Carvalho (2003) isso não se reflete necessariamente no padrão de carreiras, pois, mesmo que socializados em círculos restritos durante a formação, o mais comum era que também ocupassem cargos regionais, e não apenas no centro do Império. É notório haver um aproveitamento de todas as oportunidades de cargos disponíveis.

Percebemos também que apenas no começo do período havia uma significativa, ainda que pequena, abertura a políticos novatos. Mas é necessário notar que as carreiras não evoluem necessariamente respeitando a proporção da passagem do tempo.

É interessante o fato de que já na inauguração do Senado, o padrão era de políticos experientes. Tal fato indica haver continuidade entre ocupantes de cargos públicos na Colônia, o que sugere ter influenciado uma precoce institucionalização do cargo. 
Ainda que os dados analisados não exponham os detalhes da carreira política destes indivíduos, sendo necessárias variáveis quantitativas mais específicas, tampouco podem dar uma resposta definitiva para o quanto estes atores eram profissionais políticos. O que podemos confirmar é o que autores como Leite (1978) e Carvalho (2003) propuseram: um alto nível de experiência política era um critério relevante no recrutamento para o cargo de senador no Brasil Império. O que nega a hipótese de que era um fator desimportante, sendo um cargo facilmente permeável a novatos e políticos ocasionais.

Estes resultados são fortes indícios de profissionalização política, provavelmente, não de indivíduos que viviam da política, considerando que até onde sabemos a grande maioria eram notáveis econômicos. Mas com certeza, os dados mostram que eram políticos que viviam para a política.

A profissionalização política está historicamente ligada ao surgimento de uma classe de políticos representantes de interesses diversos, não necessariamente coincidentes com os seus interesses pessoais. Ainda que não se trate de representação de setores amplos da sociedade, e considerando a crítica de Dolhnikoff (2011) referente à ausência de representatividade por não haver eleições periódicas, o estudo remete indiretamente ao debate historiográfico da representatividade do regime, ainda que esteja longe de explicá-lo definitivamente.

Os resultados mostram, ainda, que a carreira parlamentar senatorial e a deputação estavam relacionadas, o que nos sugere uma especialização específica para cargos legislativos.

Por fim, indiretamente, o fato de ter sido encontrado um critério não personalista no recrutamento faz do estudo um subsidio empírico às teses heterodoxas da historiografia nacional, nomeadamente, Dolhnikoff (2011) e Carvalho (2003), de que havia certa autonomia da esfera política frente a interesses puramente econômicos e pessoais.

\section{REFERÊNCIAS}

BLACK, G., 1970. A. Theory of Professionalization in Politics. The American Political Science Review, v. 64, n. 3, 1970, pp. 865-878.

BOLOGNESI, B. e MEDEIROS, P. Aspectos motivacionais do recrutamento político: um estudo inicial dos candidatos a deputado federal no Brasil (2010) Paraná Eleitoral, v. 3 n. 2, 2014, pp. 99-124.

CARVALHO, J. M. A construção da ordem: a elite política imperial; Teatro de sombras: a política imperial. Rio de Janeiro: Civilização Brasileira, 2003.

CZUDNOWSKI, M. M. Political Recruitment. In: F. I. GREENSTEIN e N. W. POLSBY (eds.). Micropolitical Theory. Handbook of Political Science. vol. 2, Massachusetts, Addison-Wesley Publishing Company, 1975, pp. 155-242.

DOLHNIKOFF, M. O lugar das elites regionais. REVISTA USP, São Paulo, n.58, 2003, pp. 116-133.

O pacto imperial: origens do federalismo no Brasil do século XIX. São Paulo: Globo, 2005.

Representação política no Império. Anais do XXVI Simpósio Nacional de História ANPUH, São Paulo, 2011, pp.1-32.

Governo representativo e legislação eleitoral no Brasil do Século XIX. Journal of Iberian and Latin American Research, Vol. 20, 2014, pp. 66-82.

FAORO, R. Os donos do poder: formação do patronato político brasileiro, edição revista acrescida de índice remissivo. Rio de Janeiro: Globo, 1958. 
FERRAZ, S. A. Dinâmica Política do Parlamentarismo do Império: Gabinetes, Câmara dos deputados e Poder Moderador (1840-1889). Anais do III Seminário Discente da Pós-Graduação em Ciência Politica da USP, 2013.

GRAHAM, R. Clientelismo e política no Brasil do século XIX. Rio de Janeiro: Editora UFRJ, 1997.

LEITE, B. O Senado nos anos finais do Império: 1870-1889. vol. 2, Brasília, Editora Universidade de Brasília, 1978.

MARTINS, M. A velha arte de governar: o Conselho de Estado no Brasil Imperial. TOPOI, v. 7, n. 12, 2006, pp. 178-221.

MASSIMO, L. e COSTA, L. D. Aumentando o campo para jogar: circulação política entre Senadores brasileiros durante a Primeira República. Núcleo de Pesquisa em Sociologia Política Brasileira/UFPR, 2014. NEIVA, P. e IZUMI, M. Perfil profissional e distribuição regional dos senadores brasileiros em dois séculos de história. Revista Brasileira de Ciências Sociais, v. 29 n. 84, 2014, pp.165-188.

PERISSINOTTO, R e VEIGA, L. Profissionalização política, processo seletivo e recursos partidários: uma análise da percepção dos candidatos do PT, PMDB, PSDB e DEM nas eleições para Deputado Federal de 2010. OPINIÃO PÚBLICA, Campinas, vol. 20, n. 1, 2014, pp. 49-66.

PREWITT, K. The Recruitment of Political Leaders: A Study of Citizen-Politicians. The Bobbs-Merril Company Inc., New York, 1970.

STONE, L. Prosopografia. Revista de Sociologia e Política, v. 19, n. 39, 2011, pp. 115-137.

VARGAS, J. M. "Um negócio entre famílias". A elite política do Rio Grande do Sul (1868-1889). In. História social de elites / Organizador Flavio M. Heinz. - São Leopoldo: Oikos, 2011.

WEBER, M., 1985. Ensayos de sociología contemporánea I. Barcelona: Planeta- De Agostini.

\section{FONTES AUXILIARES}

Anais do Senado do Império, (1826)-(1870 a 1889), Rio de Janeiro, Tipografia do Diário do Rio de Janeiro, 1826 e 1870 a 1889.

CARVALHO MOREIRA F. I. e PREREIRA DE BARROS F. M. I., 1855. Constituição do Império do Brasil: seguida do Ato adicional, Lei da sua interpretação e Lei do Conselho de Estado; aumentada das leis regulamentares, decretos, avisos, ordens e portarias que lhes são relativas e que desde sua promulgação até o presente se têm expedido. Rio de Janeiro.

JAVARI, B. de. Organizações e Programas Ministeriais. Rio de Janeiro, Ministério da Justiça/Arquivo Nacional, 1962. 